\section{Screening for abdominal aortic aneurysms}

EDITOR, - P L Harris concludes his review of the issues concerning screening for abdominal aortic aneurysms by advocating a national screening programme.' We suggest that more caution is required because current evidence is inadequate to permit judgments on the merits of screening.

The rate of detection of patients with an aneurysm who would benefit from intervention might be extremely low. The prevalence of aneurysms among men in their late 60 s and early 70 s is roughly $2 \%$, but the prevalence of large aneurysms, which are in most danger of rupturing, is much less. Among 4331 subjects in four recent surveys only seven $(0 \cdot 16 \%)$ had an aneurysm $>6$ $\mathrm{cm}$ in diameter and $36(0.83 \%)$ had an aneurysm of $4.5-5.9 \mathrm{~cm}$ in diameter. ${ }^{2.5}$ Most surgeons would operate on aneurysms $>5.5 \mathrm{~cm}$ and observe those $<4.0 \mathrm{~cm}$. Disagreement on whether to operate on those of $4 \cdot 0-5 \cdot 5 \mathrm{~cm}$ will not be resolved until the results of the United Kingdom small aneurysm trial are available. Given current surgical practice, only about $15-20 \%$ of aneurysms $>3.0 \mathrm{~cm}$ detected on screening would be sufficiently large to warrant early surgery.

Many smaller aneurysms may expand so that surgery is justified later, but a major problem in deciding whether to detect smaller aneurysms is that the growth and rupture rates of aneurysms $<5.5 \mathrm{~cm}$ in the general population are not well established. The one follow up study quoted by Harris $^{6}$ reflects a general deficiency in this field: follow up studies are based on selected hospital patients or are too small to provide answers within reasonable confidence intervals. It could be that small aneurysms in the community are not worth detecting because the risks of growth, rupture, and death are slight in relation to the hazards of surgery, the cost of repeated ultrasound examinations, and anxiety for the patient.

To determine the need for a screening programme, information is required on the expected increase in life expectancy and the quality of the added years. Attempts to find out whether screening is beneficial by amalgamating the results of studies, including by use of computer simulation techniques, ${ }^{7}$ rely on too many assumptions - for example, that the study populations and measurement techniques are comparable. What is needed is to build on the information on feasibility, compliance, and detection rates provided by screening surveys ${ }^{2.5}$ and to conduct a randomised controlled trial comparing screening and unscreened populations. The costs and benefits of mounting a national screening programme would then have to be weighed up against other priorities in the health service.

F G R FOWKES

C V RUCKLEY

Wolfson Unit for Prevention of

Peripheral Vascular Diseases,

University of Edinburgh,

Edinburgh EH8 9AG

J T POWELL

Department of Surgery,

Charing Cross Hospital,

London W6 8RF

1 Harris PL. Reducing mortality from abdominal aortic aneurysms: need for a national screening programme. BMF 1992;305:6979. (19 September.)

\section{Advice to authors}

Priority will be given to letters that are less than 400 words long and are typed with double spacing. All authors should sign the letter. Please enclose a stamped addressed envelope for acknowledgment.

2 Collin J, Araujo L, Walton J, Lindsell D. Oxford screening programme for abdominal aortic aneurysm in men aged 65 to 74 years. Lancet 1988 ;ii:613-5.

3 Scott RAP, Ashton HA, Kay DN. Routine ultrasound screening in management of abdominal aortic aneurysm. BMF 1988;296: 1709-10.

4 O'Kelly TJ, Heather BP. General practice based population screening for abdominal aortic aneurysms: a pilot study. Brf Surg 1989;76:479-80.

5 Akkersdijk GJM, Puylaert JBCM, de Vries AC. Abdominal aortic aneurysm as an incidental finding in abdominal ultrasonography. Br F Surg 1991;78:1261-3.

6 Szilagyi DE, Elliot JP, Smith RF. Clinical fate of the patient with Szilagyi DE, Eliot JP, Smith RF. Clinical fate of the patient with
asymptomatic abdominal aortic aneurysm and unfit for asymptomatic abdominal aortic aneurysm
surgical treatment. Arch Surg 1972;104:600-6.

7 Bergqvist D, Bengtsson H. Is screening for abdominal aortic aneurysm worthwhile? Ann Chir Gynaecol 1992;81:203-8.

EDITOR, - P L Harris recommends establishing a mass screening programme for abdominal aortic aneurysm. ${ }^{1}$ We recently evaluated such a proposal for Dudley and South Birmingham Health Authorities and concluded that it is not appropriate to fund such a programme at present.

The evidence of benefit from screening is drawn primarily from an economic analysis by Collin, ${ }^{2}$ a study that is unsatisfactory in both its interpretation of published work and economic methodology. The key determinant in the benefit of screening for abdominal aortic aneurysm is the additional life expectancy of a screened cohort compared with a non-screened one: the values obtained by Collin cannot be supported by the published work. The limited evidence available suggests that life expectancy after elective repair of an aneurysm is shorter than that of an equivalent normal population ${ }^{3+}$ owing to considerable comorbidity. ${ }^{5}$ In addition Collin's analysis makes no reference to discounting of costs and benefits incurred over time.

A recent study, based on a thorough review of the available evidence, showed that there was no net increase in life expectancy between cohorts (J M Mason et al, health economics study group, $\mathrm{St}$ Andrews, Scotland, June 1992). It was concluded that much better information was required on the annual rate of rupture of aneurysms, how this rate varies with age, and the survival prospects of patients after elective and emergency resection. Although Harris quotes a rupture rate of $7 \%$ a year for aneurysms of $5.5 \mathrm{~cm}$ or over, other evidence suggests that it may be much lower. ${ }^{67}$ Most of the rupture rates have been derived from follow up of people not fit for surgery, who are at greater risk than a true control group.

To say that the aetiology of abdominal aortic aneurysm is uncertain ignores much evidence indicating that the condition shares major risk factors with arterial disease in general, ${ }^{89}$ in particular smoking and hypertension. Resources to add years of life ${ }^{10}$ may be more appropriately used in primary prevention, with the possibility of an additional impact on major causes of death such as ischaemic heart disease and stroke.

Given the uncertainties discussed above, establishing mass screening for abdominal aortic aneurysm is inappropriate at present. Properly conducted randomised controlled trials are needed to resolve these uncertainties; they could also study groups at higher risk of rupture such as hypertensive subjects. Only then will we have sufficient knowledge to make an informed decision about the risks and benefits of such a programme.

Centre for Health Economics,

J M MASON

York University,

Dudley Health Authority,

A WAKEMAN

Dudley DY1 2DD

Institute of Public and Environmental Health,

Birmingham Medical School

Birmingham B152\%T

1 Harris PL. Reducing the mortality from abdominal aortic aneurysms: need for a national screening programme. BMY

2 Collin J. The value of screening for abdominal aortic aneurysm by ultrasound. In: Greenhalgh RM, Marrick JA, eds. The cause and management of aneurysms. London: Saunders, 1990.

3 Soreide O, Lillestol J, Christiensen O, Grimsgaard C, Myhr HO, Solheim K, et al. Abdominal aortic aneurysms: survival analysis of four hundred thirty-four patients. Surgery 1982; 91:188-93.

4 Nachbur E, Gut A, Sigrist S. Prognostic factors in the surgical treatment of aorto-iliac aneurysmal disease. 7 Cardiovasc Sury 1987;28:469-78.

5 Hertzer NR, Beven EG, Young JR, O'Hara PJ, Ruschhaupt WF III, Graor RA, et al. Coronary artery disease in peripheral vascular patients. A classification of 1,000 coronary angiovascular patients. A classification of 1,000 coronary angiograms and $\mathrm{r}$

6 Nevitt MP, Ballard DJ, Hallett JW Jr. Prognosis of abdominal aortic aneurysms. N Engl f Med 1989;321:1009-14.

7 Guirgis EM, Barber GG. The natural history of abdominal aortic aneurysms. Am $\mathcal{F}$ Surg 1991;162:481-3.

8 Allen PIM. Screening for abdominal aortic aneurysm. Biomed Pharmacother 1988;42:451-4.

9 Thurmond AS, Semler HJ. Abdominal aortic aneurysm: incidence in a population at risk. $\mathcal{F}$ Cardiovasc Surg 1986;27 $457-60$.

10 Secretary of State for Health. The health of the nation: a strategy for health in England. London: HMSO, 1992.

EDITOR,-P L Harris makes a compelling case for setting up a national screening programme for abdominal aortic aneurysms.' A high risk group not mentioned in the article is patients with hypertension. In this group the single screening scan at 65 for men only that Harris suggests would not be adequate. We briefly report our experiences in screening a general practice population of hypertensive patients to support this claim.

Over the past 18 months in Mid-Glamorgan we have screened 851 hypertensive patients ( 463 men, 388 women) drawn from the registers of three local group practices. The mean age of these patients at screening was 63.5 years. In the 463 men 36 aneurysms were found, of which 12 were over $3.5 \mathrm{~cm}$, giving an overall incidence of $7.8 \%$ and an incidence of aneurysms over $3.5 \mathrm{~cm}$ of $2.6 \%$. In the 216 men aged 65 and over, however, the incidence rose to $10.6 \%$ (23 aneurysms; seven $(3 \cdot 2 \%)$ aneurysms over $3.5 \mathrm{~cm})$. In the 247 men under 65 the incidence of aneurysms was $5 \cdot 3 \%$ (13 aneurysms) and five $(2.0 \%)$ of these men had aneurysms over $3.5 \mathrm{~cm}$. Eight men had elective repairs of the aneurysm as a result of ultrasound screening, and the remainder are having regular repeat scanning.

Little is known about the natural course of aneurysms in hypertensive patients. Three of our patients requiring elective repair were under 65 